\title{
Online learning in management education: an empirical study of the role of personality traits
}

\author{
Otmar E. Varela • John James Cater III • \\ Norbert Michel
}

(C) Springer Science+Business Media, LLC 2012

\begin{abstract}
In this study we seek to better understand the outcomes of online education by observing the role of learners' personality traits. Under the premise that the behaviors that maximize learning are contingent on the delivery method, we compared learning outcomes of students participating in four sections of an undergraduate principles of management course - three sections were taught using the online approach and one section was taught using the classroom teaching approach $(N=132)$. Following a multi-group quasi-experimental design, we controlled for differences in teaching delivery styles between the online and traditional classes. Then, we utilized students' personalities as the key independent variable of learning across classes. Our results corroborate that personality is an independent variable worthy of consideration in online settings. Results also suggest that future research in these settings benefits from considering narrow descriptions of personality as opposed to traditional broad traits (e.g., the big-five model). Specifically, we argue that online education demands a particular set of behavioral patterns (i.e., low gregariousness, achievement orientation) necessary to navigate the idiosyncrasies of online education (e.g., social isolation, schedule flexibility). We discuss the theoretical implications of our results in the context of online education and offer practical suggestions for online teaching design.
\end{abstract}

O. E. Varela

Department of Management and Marketing, University of Arkansas-Little Rock, Little Rock, AR, USA

e-mail: oxvarela@ualr.edu

J. J. Cater III ( $($ )

Department of Management and Marketing, The University of Texas at Tyler, Tyler, TX 75799, USA

e-mail: jim.cater59@yahoo.com

N. Michel

Department of Finance and Economics, Nicholls State University, Thibodaux, LA 70310, USA

e-mail: norbert.michel@nicholls.edu 
Keywords Online learning - Broad and narrow personality traits - Management education

\section{Introduction}

Online education is an accepted teaching approach in higher education as approximately $96 \%$ of the largest colleges and universities in the United States offer online courses (Chapman and Henderson 2010). Online is commonly considered a form of distance education because students are physically separated from each other and the instructor (Smith and Mitry 2004). This teaching approach features electronic learning or e-learning, which relies on computer network technology, often via the internet, to transfer information from instructors to participants and vice versa (Welsh et al. 2003).

Substantial research has followed the growing academic interest in online education, with special attention to understanding the effectiveness of the online teaching approach compared to classroom instruction. Various meta-analyses have compiled these studies (e.g., Jahng et al. 2007; Sitzmann et al. 2006). Echoing previous findings, a recent meta-analysis sponsored by the U. S. Department of Education (Means et al. 2010) reports that students who participated in online conditions performed similarly to those in classroom settings, with no significant differences in learning outcomes $(d=.05 ; k=27 ; p>.05)$. Furthermore, a direct comparison between teaching blended conditions (traditional and online methods combined) versus entirely face-to-face shows statistically significant differences in learning outcomes in favor of blended environments $(d=.35 ; k=23, p<.05)$. Taken together, meta-analytic results indicate that online delivery produces comparable outcomes to traditional methods, leading scholars to argue that research should move beyond simple online versus classroom comparisons. As Abrami et al. (2011, p. 84) state, "there is little else to learn about the nature of distance education and classroom instruction from comparative studies." Rather, research is needed to advance our knowledge of the conditions moderating the effectiveness of online teaching. This line of investigation is especially relevant when one observes the dispersion of outcomes in online research. For example, the effect sizes $(d)$ of the studies included in Bernard et al.'s (2004) meta-analysis ranged from -1.31 to +1.41 . Bernard and colleagues also highlight the substantial heterogeneity of research outcomes in online education in a separate meta-analysis (see Bernard et al. 2004). Together, these studies stress the need for more research aimed at unveiling factors (moderators) that provoke such disparity of results.

In this study we explore the role of learners' attributes in online education, perhaps the most significant gap in this literature. We searched for empirical works published over the last decade in five leading journals in the field of online education: Computers and Education, Review of Educational Research, International Review of Research in Open and Distance Education, Journal of Computing in Higher Education, and Journal of Distance Education. Our queries combined the words online, distance, learning, and education, which resulted in a total of 56 empirical articles. Two judges were asked to independently classify the 56 articles 
according to their research focus into four options: (a) outputs (e.g., students' learning, satisfaction), (b) delivery strategy (e.g., technology to be used, communication strategies), (c) contextual factors (e.g., studies on industry evolution) and (d) individual predictors of online learning (e.g., emotional intelligence, personality). The final classification, which was reached by consensus between the two judges, shows that $39 \%$ of empirical studies attempt to answer questions with respect to delivery strategies (e.g., synchronous vs. asynchronous activities, immersive learning technologies). Contextual factors accounted for $30 \%$ of the studies, while learning outputs and individual predictors were the areas receiving less attention (18 and $13 \%$ respectively).

We do not claim that our search is exhaustive, nor that this is conclusive evidence of the research tendencies in online education, but the classification clearly indicates the heavy interest in studying the role of pedagogical strategies in online learning. While these studies have been instrumental in advancing our understanding of ideal teaching strategies in online settings, the inattention to learners' attributes still represents an important knowledge gap. Several areas of knowledge in the educational field (e.g., training; face-to-face learning) consistently report the pivotal role of individual attributes in learning (e.g., Colquitt et al. 2000). In a recent metaanalysis, Poropat (2009, p. 333) further accentuates: "personality should take a more prominent place in future theories of academic performance." Because learning demands continuous effort from students to capture and process novel information, those attributes that may explain steady individual efforts across settings (e.g., personality) have prevailed in research as the most significant predictors of learning (Ree and Earles 1991).

This study addresses the knowledge gap above by testing the role of personality traits in online learning. Under the assumption that online settings demand a different set of behavioral patterns from learners than do face-to-face settings, we test the impact of personality on online education. Our research is guided by the question: Which personality traits facilitate learning in online settings? Toward this goal, the next section describes the characteristics of online education. Then, we hypothesize about the fit of specific personality traits to online settings.

\section{Characteristics of online education}

Flexible schedules seem to be one of the most appealing attributes of online education (e.g., Gagne and Shepherd 2001). The broad accessibility to technology enables online students to do class work any time anywhere. Consequently, the pace of learning in online courses heavily relies on the students, who can choose convenient times to concentrate on learning. This feature has proven to be of great value, especially to students facing irregular schedules (e.g., part-time workers, parents; Hiltz and Wellman 1997). Other advantages ascribed to online learning include reduced travel time and expenses. Avoiding periodic commuting implies a more efficient use of time and resources which is enticing to students, especially those located far away from campuses (Gagne and Shepherd 2001; Hay et al. 2004). This benefit may be even more consequential to students living in environments where weather may create hazardous travel conditions. Investigations show that 
students are generally satisfied with online classes (e.g., Campbell et al. 2002). This satisfaction may be a result of gratefulness for relief from the inconvenience and expense of commuting, rigid schedules, and a more convenient balance between classes and other responsibilities (e.g., work). Online students appeared to be willing to accept a tradeoff between flexibility and convenience in exchange for perceived qualitative drawbacks (lack of face-to-face interactions), often associated with limitations in course delivery (Vamosi et al. 2004).

On the opposite side, online students report frustration because of waiting an unpredictable amount of time to receive reactions or feedback (Hiltz and Wellman 1997). Consequently, there may be a negative impact on student involvement and participation in online classes (Arbaugh 2000). Students may feel isolated, lose the informal learning opportunities that occur with peer interaction, and lack a sense of learning community (Blunt 2001). Some students have claimed that establishing close personal relationships was more difficult in online classes and, as such, it was easier to stop participating in class when other areas of their lives became busy (Hiltz and Wellman 1997). In some cases, disproportionately high dropout rates have occurred in online courses, arguably attributable to the restrictions of the online learning communities (Bishop et al. 2007; Sapp and Simon 2005). The dynamics of interaction between instructors and students may undermine the commitment of students to learn (Dellana et al. 2000). Smith and Mitry (2004) fear that unless faculty build a systematic dialog with students, online courses may devolve into a form of correspondence class.

Personality in online education

Formal education is multidimensional in nature in the sense that numerous factors (e.g., instructor's style, delivery strategy) may influence learning results (Vonderwell and Zachariah 2005). This multidimensionality suggests that each educational event is unique; it is a particular combination of the various dimensions that converge in learning. To maximize results, learners should recognize and adapt to the particularities of the event. They need to ensure that their behavioral efforts match the idiosyncrasies of a focal course. This assumption underlies studies emphasizing personality traits in education where learning is partially seen as the fit between learners' behavioral patterns and the characteristics of the learning event.

Personality refers to an individual's social reputation; behavioral patterns that govern individuals' responses across situations (Hogan 1991). As noted, these behavioral tendencies have been instrumental in explaining learning outcomes in a variety of ways. For instance, the dependability and achievement orientations that characterize individuals high in conscientiousness are associated with a strong motivation to learn; a drive that, in turn, exhibits substantial connections with learning outcomes (Colquitt et al. 2000; Rowold 2007). Similarly, the trait referred to as agreeableness has been associated with learning, primarily by nurturing positive predispositions to learn. Because individuals high in agreeableness exhibit kindness and consideration, they are more willing to overcome and adapt to the inconveniences occurring in educational events (Sitzmann et al. 2008). Extraversion and openness to experience have also been linked to learning. Researchers have 
specifically referred to the enthusiasm and willingness to be exposed to novel situations associated with these two traits to rationalize the connection between personality and learning results (Ferris et al. 1985). In summary, numerous studies in the learning literature have already identified behavioral patterns that meaningfully contribute to learning.

It is worth noting that the ability of personality traits to explain phenomena is expected to increase in environments wherein individual behaviors are less constrained by contextual clues (e.g., social settings, organizational formal roles; see Mischel 1968). This notion is particularly relevant in online contexts where learners' discretion over learning behaviors augments. Compared to face-to-face classes, online students are less confined to fulfill social expectations. They possess more freedom over the nature and frequency of social interactions. Consequently, we anticipate personality to be a prominent independent variable of learning in online settings.

In this study we explore the role of the personality traits included in the domain of the Big Five model (i.e., extraversion, conscientiousness, agreeableness, openness to experience, and intellect), arguably the most scrutinized personality framework in research (Mount and Barrick 1995). By choosing the Big Five model, we do not imply the superiority of this approach; nor is it our intention to suggest that traits not directly addressed in the model (e.g., self-esteem) lack relevance for learning. Our goal is chiefly to build on a personality framework that has received substantial support in the field (e.g., Grucza and Goldberg 2007; Thompson 2008), as a mean to facilitate understanding and generalization of our findings.

Additionally, in efforts to increase validity coefficients of personality traits, subcomponents of the Big Five traits have been derived in research (e.g., see Hogan and Ones 1997). Because the Big Five model is viewed as a coarse description of individuals' behavioral patterns (e.g., Crant 1995), scholars have called for more attention to narrower sub-traits in order to increase the specificity and statistical power of predictors grounded on personality traits (e.g., Depue and Collins 1999). In summary, in this study we (a) explore the role of personality traits as likely antecedents of learning in online settings and (b) simultaneously consider broad and narrow descriptions of personality traits as a mean to overcome the predictive constraints that unrefined traits might create.

\section{Hypotheses}

It is our position that two personality traits play a fundamental role in online education: extraversion (low; i.e., introversion) and conscientiousness. Extraversion represents the tendency to seek gratification in what is outside the self (Jung 1921). Extraverted subjects place their energy in the outer world. As such, they tend to be talkative, exhibit enthusiasm in social settings, and consistently seek human interaction (Moberg 2001). These behavioral patterns, however, do not appear to fit online education, where social interaction is constrained. In online settings, learning occurs primarily through autonomous and introspective efforts rather than through the vivid exchanges characterizing traditional settings. Indeed, studies report that 
introverted subjects prefer online settings (Anitsal et al. 2008; Harrington and Loffredo 2010), suggesting that introverted behavioral patterns (e.g., seeking independent work, preference for isolation) better fit the idiosyncrasies of online education. We expect this introversion-online match to increase the satisfaction of introverted subjects who work in online settings, ultimately strengthening learning outcomes. Affect scholars have significantly highlighted the relevance of satisfaction (i.e., positive affects) in learning (Forgas and Vargas 2004). Pleasurable educational experiences are instrumental in boosting engagement and enhancing the cognitions necessary to associate abstract ideas, integrate novel information, and develop knowledge (Isen 2004; Varela et al. 2011). In online settings, we expect these positive experiences to prevail in introverted as opposed to extroverted subjects. Consequently:

Hypothesis 1: Introversion is a stronger predictor of learning outcomes in online settings than face-to-face contexts.

Conscientiousness has been strongly linked to learning (e.g., Ree and Earles 1991). Because conscientiousness captures the degree of order, persistence, and dependability of individuals, subjects high in this trait tend to exhibit elevated levels of achievement across situations (Barrick et al. 2001). It is our position that conscientiousness plays a stronger role in online settings than face-to-face ones. Online learning was characterized above as a flexible delivery method; one that accommodates to learners' circumstances. Compared to face-to-face environments, online learners possess more control over the learning pace as they have more freedom to choose the timing of completing course work. Under these circumstances, learning relies heavily on the learners' self-discipline and self-control rather than the social influence (i.e., pressure) that face-to-face interaction may exert. Therefore, we propose the following.

Hypothesis 2: Conscientiousness is a stronger predictor of learning outcomes in online settings than face-to-face ones.

As an attempt to further specify the behavioral patterns predicting learning outcomes in online settings, we now focus our attention on narrow personality traits within the domain of extraversion and conscientiousness. Two main subcomponents tend to converge in the domain of extraversion: (a) interpersonal engagement, or tendencies to seek for interpersonal bonds, and (b) impulsivity, or the energy and enthusiasm exhibited in social settings (Depue and Collins 1999). Given the scant social integration in online education, we center on the interpersonal-engagement subcomponent. Specifically, we maintain that the low pole of interpersonal engagement (referred to hereafter as low gregariousness) is pivotal in explaining learning in online settings. Indeed, Blunt (2001) reports that online learners experience feelings of isolation and lack a sense of learning community. These experiences might be more satisfactory for individuals who confine themselves from social settings (low in gregariousness), regardless of their impulsivity level (the second component of extraversion). As such, we anticipate the low pole of the narrow trait (gregariousness) to outperform extraversion (the broad trait) in predicting learning outcomes in online education. Formally: 
Hypothesis 3: Low gregariousness is a stronger predictor of learning outcomes in online settings than extraversion.

Conscientiousness has also been split into narrower traits with some consensus emerging around four sub-factors: achievement, dependability, cautiousness, and order (e.g., Hogan and Ones 1997). In this study we center our attention on two subfactors, achievement and dependability, as key predictors of online education. Achievement reflects tendencies to strive for success. Individuals high in this narrow trait tend to persevere, even in the face of adversity. This tendency may be instrumental especially in the constrained delivery situations that characterize online learning. As mentioned above, problems accruing to online education involve frustrations because of the unpredictability of the timing of others' participation, lack of control of instructors' feedback, and restricted communication lacking faceto-face clues. Under these circumstances, we maintain that students' propensity to strive for achievement is the fundamental pattern in explaining success in online education. As such:

Hypothesis 4: Achievement (a narrow trait) is a stronger predictor of learning outcomes in online settings than conscientiousness (broad trait).

A similar rationale may be applied to dependability, a second narrow trait of conscientiousness. Dependability captures the tendency to experience a strong sense of accountability and adjustment to pre-established regulations. Individuals high in this trait exhibit high self-discipline and feel compelled to follow directions. As such, this narrow trait, more so than a broad definition of conscientiousness, might better explain learning outcomes in circumstances characterized by a high degree of discretion, such as those in online education. Formally:

Hypothesis 5: Dependability (a narrow trait) is a stronger predictor of learning outcomes in online settings than conscientiousness (broad trait).

\section{Method}

Participants and procedures

The study was undertaken at a southern regional university with an enrollment of approximately 7,000 students. We conducted our study in four sections of a Principles of Management class. Three sections of the course were taught online (with a total of 72 students) and one was taught in the classroom (with a total of 60 students). The university restricted the number of students to 25 in each online class-this rule was beyond the control of the course instructor. The main reason for this restriction given to the course instructor was to increase the learning experience of the students allowing for the instructor to give more attention to each student.

Characteristics of the students in the study were as follows. The online group was composed of a smaller percentage of males than the traditional section (32 vs. $42 \%$ ), a smaller percentage of business majors than the traditional section (49 vs. $65 \%$ ), and a larger percentage of seniors than the traditional section (56 vs. $28 \%$ ). 
While gender differences were statistically insignificant across the two sections, the differences in the proportion of business majors and seniors across the groups were both statistically significant $(p<05)$. Controlling for these differences in regression analyses do not materially impact the results presented below.

Each section was taught by the same instructor during the course of three semesters. The instructor is an assistant professor in the college of business, has approximately 8 years of teaching experience, and regularly receives "above average" student evaluations. The same textbook, power point slides, chapter review questions, case study exercises, and exams were used in the online and classroom sections. Both online and classroom students watched the same videos and answered questions about them in case study exercises. The online classes participated in weekly chapter review quizzes in multiple-choice format, while the classroom section participated in similar quizzes in short answer format. The classroom section received lectures from the professor, while the online class did not. To facilitate interaction among the students and between the instructor and the students, the online classes participated in discussion board exercises. The discussion board questions were similar to those used in the classroom lectures.

\section{Measures}

\section{Learning}

Student cognitive outcomes were measured with the scores on three multiple choice exams, each one consisting of 50 questions with four alternative answers per question. The three exams were not cumulative and each exam covered about one-third of the course material. The learning measure is the student-level average (mean) score of the three exams. Students in all sections took the same exams. The exams were administered in the same exact format, both online and classroom students took the proctored exams by completing Scantron forms. The exams were proctored by the course professor for all students, except for four students in the online sections who were geographically distant from the university campus. Those students' exams were proctored by local college professors or city librarians with the approval of the course professor. The course professor had previously used the exams in six classroom sections and two online sections of the course. During the eight prior classes, the course professor worked to eliminate questions which the students missed in very high percentages or answered correctly in extremely high percentages. The resulting exams were able to create a grade dispersion among the students from 100-42\%. The items measured different facets of twelve common management topics including social responsibility, decision making, planning, leadership, and operations. The scores of the three tests were equally weighted and used as a proxy for learning. That is, declarative knowledge retained from class material.

\section{Broad traits: conscientiousness and extraversion}

Self-reported data on conscientiousness and extraversion were collected with Goldberg's (1992) personality questionnaire. The measure consists of 100 items 
divided in blocks of 20 items for each one of the Big Five personality traits. For this study, we applied the 40 items (20 items per trait) for conscientiousness and extraversion. Items ask participants to assess the extent to which a focal adjective describes them. Examples of items assessing conscientiousness include "careful," "efficient," and "organized." Examples of items assessing extraversion include "energetic," "assertive," and "shy." A 5-point scale anchored between "extremely inaccurate" to "extremely accurate" accompanied the items. Goldberg (1992) has reported strong psychometric properties for the 100-marker personality questionnaire. Our results show that internal consistency reliabilities (Cronbach's alpha) for the conscientiousness and extraversion scales reached accepted standards (.85 for conscientiousness and .94 for extraversion).

\section{Narrow traits: gregariousness, achievement, and dependability}

To evaluate the narrow traits under study, the items loading into extraversion and conscientiousness were separately classified. Toward this goal, two judges independently classified the 20 items of extraversion into the two corresponding sub-traits: gregariousness and impulsivity (Depue and Collins 1999). Then, judges were asked to reach a final categorization by consensus. Eleven of the twenty items from the extraversion scale were selected as indicators of gregariousness, while the remaining nine items were considered as indicators of impulsivity. To test the twofactor structure of extraversion's narrower traits, confirmatory factor analysis was conducted. Because the initial results did not reach accepted standards (Comparative Fit Index-CFI $=.864$; Normed Fit Index-NFI $=.812$; Root Mean Square Error of Approximation-RMSEA $=.08$ ), Lagrange Multiplier statistics were observed. The dropping of one item of the impulsivity factor and a double loading of another item boosted confirmatory factor analysis results to accepted standards $(\mathrm{CFI}=.905, \mathrm{NFI}=.887$; RMSEA $=.05)$. Cronbach's alpha reliabilities of the two narrow traits (.85 for gregariousness and .78 for energy) lend further support to the final categorization.

A similar procedure was followed in distributing the items from the conscientiousness scale into the four subcomponents: achievement, dependability, cautiousness, and order (Hogan and Ones 1997). Initially independently and then by consensus, two judges categorized the list of 20 items into the four narrow traits. Six items were selected to evaluate achievement. A similar number of items were selected as indicators of dependability. The remaining eight items were equally divided between cautiousness and order. Confirmatory factor analysis was run to test the judges' categorization with results approaching acceptable standards $(\mathrm{CFI}=.878$; NFI $=.858$; RMSEA $=.071)$. Following Lagrange Multiplier Statistics, two items were double loaded (none of them from achievement or dependability factors) and one item from cautiousness was dropped. Fit statistics $(\mathrm{CFI}=.911 ; \mathrm{NFI}=.899 ; \mathrm{RMSEA}=.045)$ and Cronbach's alpha reliability values (.82 for achievement, .84 for dependability; .69 for cautiousness, and .77 for order) lend further support to the final categorization. 
Experimental issues: student withdrawal and variances across courses

Range restriction (or survivor bias) tends to challenge the type of analysis in this paper as withdrawing students are left out of the final sample. Because only two students withdrew from any of the four sections included in our study, we simply dropped the two withdrawn students from the analysis.

A second experimental issue to consider is that the online classes were limited to 25 students by the university. To obtain a sizeable sample, we pooled the students in all three online classes. Naturally, this procedure brings into question whether there is a group-level data problem. If, for example, learning outcomes in the three online classes were significantly different, pooling the three sections might be questionable as contextual factors might be creating group differences between the online sections. In such a case, class sections rather than individuals should be the unit of analysis. We conducted an analysis of variance to compare learning across the three online sections. Results showed that learning outcomes were not statistically different $(p<.05)$ across sections, thereby suggesting that pooling the data is acceptable. While we acknowledge that pooling the three groups increases the chances of Type I error (by increasing sample size), the lack of significant differences in learning across sections suggests that pooling samples was adequate.

\section{Analyses and results}

Table 1 presents descriptive statistics and the set of correlations for the study variables when the entire study samples (online and classroom students) are combined. Note that the correlation between the broad trait of extraversion and its corresponding narrow sub-traits (gregariousness) is strong as the sub-traits address constructs that mainly differ in domain extension. The same can be said for the correlations between the broad trait of conscientiousness and its two narrow traits (dependability and achievement). Note also that learning in Table 1 represents the average of the three tests we used to operationalize learning. Each test consisted of 50 -items and each item was worth 2 points.

Table 1 Descriptive statistics and correlations among the study variables

\begin{tabular}{lrrrrrrrr}
\hline Variables & M & SD & 1 & 2 & 3 & 4 & 5 & 6 \\
\hline 1. Gregariousness & 3.59 & .78 & $(.85)$ & & & & & \\
2. Extraversion & 3.53 & .65 & $.80 *$ & $(.94)$ & & & & \\
3. Learning & 76.51 & 8.93 & -.13 & .04 & & & & \\
4. Conscientiousness & 3.96 & .54 & .13 & $.24 *$ & $.25 *$ & $(.85)$ & & $.04 *$ \\
5. Achievement & 3.81 & .62 & .02 & $.22 *$ & $.34 *$ & $.77 *$ & $(.82)$ \\
6. Dependability & 4.37 & .65 & $.20 *$ & $.22 *$ & .12 & $.81 *$ & $.39 *$ & $(.84)$ \\
\hline
\end{tabular}

$N=132$. Scale reliabilities are shown in parentheses. $\mathrm{M}=$ mean. $\mathrm{SD}=$ standard deviation. Average of test scores was used as a proxy for Learning

$* \mathrm{p}<.05$ 
We relied on regression analyses to test the study Hypotheses. Table 2 summarizes the results of the set of regressions. In testing Hypothesis 1, we regressed learning on the broad trait of extraversion for both study samples together (face-to-face and online). Results show that extraversion was not statistically significant $(\beta=.21$. $\mathrm{SE}=1.22 ; p>.05)$. Then, we performed similar regressions for each group (online vs. face-to-face) separately. Results for the face-to-face group indicated that extraversion failed to account for learning variance $(\beta=1.69$, $\mathrm{SE}=1.52, p>.05)$. Contrary to our expectations, results for the online group indicated that extraversion was similarly unable to explain learning in virtual settings $(\beta=-1.86, \mathrm{SE}=1.97 p>.05)$, failing to support H1. It is worth noting, however, that the signs of the regression coefficients were opposite and in the expected directions. That is, positive for face-to-face settings and negative for online classes.

In testing H2, learning was regressed on conscientiousness. Results support the ability of conscientiousness to explain learning variance across groups $(\beta=4.11$, $\mathrm{SE}=1.41, p<.05)$. Then, learning was regressed on conscientiousness, initially, in the face-to-face sample and then, in the online group. While the regressor coefficient was not statistically significant for the face-to-face group $(\beta=3.49$, $\mathrm{SE}=2.01, p>.05)$, the regression coefficient exhibits a stronger and significant effect size for the online group $(\beta=4.59$; $\mathrm{SE}=1.96, p<.05)$. Consistent with the expectations in $\mathrm{H} 2$, results corroborate that conscientiousness has a stronger ability to account for learning variance in online settings $\left(R^{2}=.079\right)$ than in face-to-face contexts $\left(R^{2}=.040\right)$.

In testing $\mathrm{H} 3$, we regressed learning on low gregariousness for the online group. Results were consistent with our expectations in the sense that this narrow trait was able to explain learning in online settings $(\beta=-4.22, \mathrm{SE}=1.56 ; p<.05)$, which was not the case for the broad trait of extraversion (see results associated with H1). A comparison between $R^{2}$ values associated with low gregariousness $\left(R^{2}=.112\right)$ and extraversion in the online group above $\left(R^{2}=.015\right)$ also suggests the superiority of low gregariousness in accounting for learning variance $\left(\Delta R^{2}=.097, p<.05\right)$, lending support to $\mathrm{H} 3$. As a post-test analysis, we also tested the role of

Table 2 Regression analyses in testing the study hypotheses

\begin{tabular}{|c|c|c|c|c|c|c|c|c|}
\hline \multirow[t]{3}{*}{ Independent variable } & \multicolumn{8}{|c|}{ Samples } \\
\hline & \multicolumn{2}{|c|}{ All together } & \multicolumn{3}{|c|}{ Face to Face } & \multicolumn{3}{|l|}{ Online } \\
\hline & $B$ & SE & $\beta$ & SE & $R^{2}$ & $\beta$ & SE & $R^{2}$ \\
\hline Extraversion & .21 & 1.22 & 1.69 & 1.52 & & -1.86 & 1.97 & \\
\hline Conscientiousness & $4.11^{*}$ & 1.41 & 3.49 & 2.01 & & $4.59^{*}$ & 1.96 & .079 \\
\hline Gregariousness & & & .136 & 1.25 & & $-4.22 *$ & 1.56 & .112 \\
\hline Achievement & $4.31^{*}$ & & & 1.70 & .087 & $5.04 *$ & 1.69 & .132 \\
\hline Dependability & & & & & & 2.99 & 1.89 & \\
\hline
\end{tabular}

$\beta$ unstandardized regression coefficient. $S E$ standard error

$* \mathrm{p}<.05$ 
gregariousness in face-to-face settings. Results indicate that this narrow trait is unable to account for learning in these settings $(\beta=.136 ; \mathrm{SE}=1.25 ; p>.05)$.

Emphasis was then placed on the two narrow traits associated with conscientiousness: achievement and dependability ( $\mathrm{H} 4$ and $\mathrm{H} 5$ respectively). We followed the same analyses procedures applied in tests of H3. Consistent with the expectations in $\mathrm{H} 4$, the narrow trait of achievement was able to explain more learning variance $\left(\beta=5.04, \mathrm{SE}=1.69 ; R^{2}=.132\right)$ than conscientiousness $\left(\beta=4.59 ; \mathrm{SE}=1.96 ; R^{2}=.079 ; \Delta R^{2}=.053, p<.05\right)$ in online settings. As an exploratory analysis, we also tested the role of achievement in the face-to-face group. Although achievement was also able to explain learning variance in these settings $(\beta=4.31 ; \mathrm{SE}=1.70, p<.05)$ a comparison of $R^{2}$ statistics suggest that achievement is a stronger predictor of learning in online contexts $\left(R^{2}=.132\right)$ than in face-to-face $\left(R^{2}=.087\right)$ ones.

Contrary to our expectations, when dependability was used as a regressor of learning in online settings, the regression coefficient did not reach statistical significance $(\beta=2.99 ; \mathrm{SE}=1.89 ; p>.05)$. Furthermore, a direct comparison of $R^{2}$ values between conscientiousness and dependability indicates loss in explained learning variance $\left(\Delta R^{2}=-.038\right)$. We interpret this outcome as indication that achievement - rather than dependability - is the central driver of learning in online settings. As such, results fail to support H5.

\section{Discussion}

In this study, we tested the role of personality traits in online education. Specifically we explored how the role of personality traits may vary as a function of the educational delivery method. In doing so, we attempted to reduce certain factors that may have confounded previous studies by having the same professor teach both the online and classroom courses at the same time period, using the same course materials (textbook, power point slides, practice questions, and case study exercises), and following the same testing procedures.

Results associated with Hypotheses 1 and 2 provide evidence to our premise suggesting that personality traits are not equally effective in predicting learning outcomes across teaching options (online vs. face-to-face). Rather, the results seem to imply that the role of personality traits in education must be viewed in light of how instruction is delivered. We interpret these outcomes as evidence indicating that learners' traits serve as adaptive mechanisms by prompting behaviors instrumental in coping with the idiosyncrasies of a focal event. Differences across learning events (e.g., interactions with classmates, workload) imply variations in the behaviors necessary to maximize results. It is our position that learners' traits facilitate - or hinder - the behaviors that a focal learning event demands. For example, an extroverted student might underperform in online settings because of his/her inability to cope with social isolation.

The notion that learners' attributes influence learning is not new. Rather, it has been at the core of a vast literature that accentuates the need to observe learners' characteristics in designing teaching methods (e.g., Kim and Atkinson 2002). Part of 
this literature has made the assumption that substantial learning gains can be obtained by matching learners' aptitudes (e.g., learning styles) with pedagogical choices (e.g., see Dunn et al. 1995). This matching-also called meshing hypothesis-predicts that results can be enhanced by fitting instruction to learners. Of note, criticisms to this meshing hypothesis are on the rise (e.g., Jonassen and Grabowski 1993). It is argued that empirical evidence in support of the meshing hypothesis is scant (Pashler et al. 2009). But even critics of this hypothesis admit that "the instruction that is optimal for a given student will often need to be guided by the aptitude, prior knowledge, and cultural assumptions that student brings to a learning task" (Pashler et al., p. 117). In other words, both defenders and detractors of the meshing hypothesis seem to converge in that learning is partially driven by learners pre-existing attributes. Our results suggest that dispositional traits (personality) are part of the set of attributes that need to be considered in understanding learning in online settings. We are not arguing that instructors must adapt their teaching strategies to learners' traits, as most of the learner-learning fit literature recommends. This sort of adaptation is an impractical suggestion that we will address later. Our point here is to underscore the plausibility of considering learners' traits as an independent variable; one that has been previously neglected in online learning research.

In online settings, we found that low gregariousness and achievement orientation were able to predict learning. We view these traits as behavioral dispositions that allow students to navigate the characteristics of online settings: working in isolation, scant social integration, and more discretion over the pace of learning. In follow up tests, where we compared the role of low gregariousness and achievement orientation in online versus traditional face-to-face settings, we found further support for the notion that these two traits are a better fit for online settings. As technology advances, more research will be needed to explore how specific technological features (e.g., Wimba, blogs) can moderate the relevance of a focal trait in online settings. But at this point, our results constitute a contribution to the field by providing initial evidence of a contingency view of personality in which the ability of traits to predict learning is contingent on the learning events' characteristics. We call for further research to provide convergent validity to our results and advance our knowledge of other traits that might facilitate online education.

Results with respect to the focus on narrow traits, compared to broad traits (Hypotheses 3 and 4), also merit attention. Scholars have argued that a rigid adherence to broad descriptions of personality traits might not be wise for the field (e.g., Borman 2004). Because broad traits tend to obscure the personality-based causes of specific phenomena, scholars have called for the use of narrower descriptors of personality (e.g., Hogan and Roberts 1996). This strategy has proven effective in strengthening the relatively low validity coefficients of personality often reported in the literature (e.g., Dudley et al. 2006). However, relying on broad personality descriptions might be appropriate when researchers explore the characteristics of broad criteria (Ones and Viswesvaran 1996). This controversy is at the core of the bandwidth-fidelity dilemma (Cronbach and Gleser 1965). Gains on predictive power by using narrow antecedents come at the price of a more superficial exploration of many other factors. In addressing this dilemma, a rule of thumb suggests that selection of predictors (in terms of domain) should be driven by 
the nature of criterion. As such, highly specific criteria should be addressed on the basis of fine-grained predictors (Hogan and Roberts 1996). Results of our study suggest that this may be the case in online education where unique setting characteristics (e.g., learner's control of delivery pace, scant social interaction) create conditions that are better explained by relying on narrow traits. This concept also provides a likely explanation as to why broad traits (e.g., extraversion) failed to fulfill the conceptual expectations of this study (e.g., see results associated with Hypothesis 1). The fact that broad traits encompass narrow components that may hold contradictory relationships across criteria (Dudley et al. 2006) dampen the role of broad traits as independent variables. Outcomes associated with Hypotheses 3 and 4 suggest that future research in the unique conditions of online learning may benefit by emphasizing narrow personality traits.

Practical implications and limitations of the study

Matching teaching strategies to specific learners' personalities might not be a wise suggestion. Instructors are not only unaware of learners' personalities but even, if that were the case, the variety of personalities limits the instructor's ability to customize teaching materials to the array of students. However, results associated with low gregariousness and achievement orientation (Hypothesis 3 and 4) might shed light on online teaching design. Broadly, our suggestion is to make online education less dependent on these two traits such that a broader spectrum of students might better adapt to online settings. This suggestion is especially important in light of the large influx of students moving into online education. As an example of a design choice that enhances the ability to match a broader spectrum of students' traits, consider the synchronous/asynchronous duality in communications. Synchronous communications, although yet online, are argued to foster a stronger sense of community than asynchronous ones (e.g., Peterson 2009). As such, sporadic synchronous events in online teaching may serve to strengthen the social components of online teaching while reducing the discretion of learners over the times allotted to learning. Such an action may reduce the role of low gregariousness and achievement orientation in online education. Regardless of the design choices, our suggestion is to make online education a more natural setting for a broader spectrum of learners.

This study is not without limitations. Although students had the choice to enter the online or classroom sections of the course, the university restriction of 25 students per online class did place a constraint on their decision. Also, by nature of the students' choice, the samples are not randomized. Consequently, generalizations of results from our quasi-experimental design as well as our ability to claim causality are limited in this study (e.g., see Stone-Romero 2011 for a discussion on causality).

\section{Conclusion}

Our study is an attempt to better understand the online teaching approach through the examination of personality traits. Our results indicate that personality traits are 
worthy of research attention in online settings. More specifically we found that: (a) low gregariousness and achievement orientation are significant predictors of learning in online settings, (b) the role of personality in education should be weighted in light of the teaching delivery method (e.g., face-to-face, online), and (c) considerations of narrow descriptions of personality traits strengthen the ability to explain learning outcomes in online settings. From our findings, we call for more attention to learners' personality traits in online research. In our view, as technology matures, online education will experience significant changes with respect to the type of electronic interactions (e.g., multimedia) between learners and instructors, further increasing the complexity of this delivery method. Such gains in complexity suggest different sets of behaviors from learners to maximize results. In other words, different relationship patterns between personality traits and learning outcomes. We view this research avenue as a promising area for further investigation and as an imperative to make online education a more malleable environment for the substantial growth of students migrating to these settings.

\section{References}

Abrami, P. C., Bernard, R. M., Bures, E. M., Borokhovski, E., \& Tamim, R. M. (2011). Interaction in distance education and online learning: Using evidence and theory to improve practice. Journal of Computing and Higher Education, 23, 82-103.

Anitsal, M. M., Anitsal, I., Barger, B., Fidan, I., \& Allen, M. R. (2008). Student evaluation of course attributes of online courses versus on ground courses: Impact of student personality traits. Proceeding from the Allied Academies International Conference, 13(1), 1-8.

Arbaugh, J. B. (2000). Virtual classroom versus physical classroom: An exploratory study of class discussion patterns and student learning in an asynchronous internet-based MBA course. Journal of Management Education, 24(2), 213-233.

Barrick, M. R., Mount, M. K., \& Judge, T. A. (2001). Personality and performance at the beginning of the new millennium: What do we know and where do we go next? International Journal of Selection and Assessment, 9, 9-22.

Bernard, R. M., Abrami, P. C., Lou, Y., Borokhovski, E., Wade, A., Wozney, I., et al. (2004a). How does distance education compare with classroom instruction? A meta-analysis of the empirical literature. Review of Educational Research, 74(3), 379-439.

Bernard, R. M., Abrami, P. C., \& Wade, A. (2004). The effects of synchronous and asynchronous distance education: A meta-analytical assessment of Simonson's Equivalency Theory. Proceedings from the Association for Educational Communications and Technology 27th conference (ED485078).

Bishop, M. J., Hyclak, T., \& Yerk-Zwicki, S. (2007). The clipper project: Lessons learned teaching an online economics course. Journal of Computing in Higher Education, 18(2), 99-120.

Blunt, R. (2001). How to build an e-learning community. e-Learning, (November): 18-22.

Borman, W. C. (2004). Introduction to the special issue: Personality and the prediction of job performance: More than the big five. Human Performance, 17(3), 267-269.

Campbell, M. C., Floyd, J., \& Sheridan, J. B. (2002). Assessment of student performance and attitudes for courses taught online versus onsite. Journal of Applied Business Research, 18(2), 45-51.

Chapman, B. F., \& Henderson, R. G. (2010). E-learning quality assurance: A perspective of business teacher educators and distance learning coordinators. The Delta Pi Epsilon Journal, LII(1), 16-31.

Colquitt, J. A., LePine, J. A., \& Noe, R. A. (2000). Toward an integrative theory of training motivation: A meta-analytic path analysis of 20 years of research. Journal of Applied Psychology, 85, 678-707.

Crant, J. M. (1995). The proactive personality scale and objective job performance among real estate agents. Journal of Applied Psychology, 80, 532-537. 
Cronbach, L. J., \& Gleser, G. C. (1965). Psychological test and personnel decisions (2nd ed.). Urbana, IL: University of Illinois Press.

Dellana, S. A., Collins, W. H., \& West, D. (2000). Online education in a management science course effectiveness and performance factors. Journal of Education for Business, 75(5), 43-47.

Depue, R. A., \& Collins, P. F. (1999). Neurobiology of the Structure of Personality: Dopamine, Facilitation of Incentive Motivation, and Extraversion. Behavioral and Brain Sciences, 22(3), 491-517.

Dudley, N. M., Orvis, K. A., Lebiecki, J. E., \& Cortina, J. M. (2006). A meta-analytic investigation of conscientiousness in the prediction of job performance: Examining the intercorrelations and the incremental validity of narrow traits. Journal of Applied Psychology, 91, 40-57.

Dunn, R., Griggs, S. A., Olson, J., Gorman, B., \& Beasley, M. (1995). A meta-analytical validation of the Dunn and Dunn learning styles model. Journal of Educational Research, 88, 353-361.

Ferris, G. R., Youngblood, S. A., \& Yates, V. L. (1985). Personality, training performance, and withdrawal: A test of the person-group fit hypothesis for organizational newcomers. Journal of Vocational Behavior, 27, 377-388.

Forgas, J. P., \& Vargas, P. T. (2004). The effects of mood on social judgment and reasoning. In M. Lewis \& J. M. Haviland-Jones (Eds.), Handbook of emotions (2nd ed., pp. 350-367). New York: Guildford Press.

Gagne, M., \& Shepherd, M. (2001). Distance learning in accounting. T H E Journal, 28(9), 2-12.

Goldberg, L. R. (1992). The development of markers for the Big-Five structure. Psychological Assessment, 4, 26-42.

Grucza, R. A., \& Goldberg, L. R. (2007). The comparative validity of 11 modern personality inventories: Predictions of behavioral acts, informant reports, and clinical indicators. Journal of Personality Assessment, 89(2), 167-187.

Harrington, R., \& Loffredo, D. A. (2010). MBTI personality and other factors that relate to preference for online versus face-to-face instruction. Internet and Higher Education, 13, 89-95.

Hay, A., Hodgkinson, M., Peltier, J. W., \& Drago, W. A. (2004). Interaction and virtual learning. Strategic Change, 13(4), 193-204.

Hiltz, S. R., \& Wellman, B. (1997). Asynchronous learning networks as a virtual classroom. Communications of the ACM, 40(9), 44-49.

Hogan, J. (1991). Personality and Personality Measurement. In M. D. Dunnette \& L. M. Hough (Eds.), Handbook of Industrial and Organizational Psychology (2nd ed., Vol. 2, pp. 327-396). Palo Alto, CA: Consulting Psychologist Press.

Hogan, J., \& Ones, D. S. (1997). Conscientiousness and integrity at work. In R. Hogan, J. Johnson, \& S. Briggs (Eds.), Handbook of personality psychology (pp. 849-870). San Diego, CA: Academic Press.

Hogan, J., \& Roberts, B. (1996). Issues and non-issues in the fidelity-bandwidth trade-off. Journal of Organizational Behavior, 17, 627-637.

Isen, A. M. (2004). Positive affect and decision making. In M. Lewis \& J. M. Haviland-Jones (Eds.), Handbook of emotions (2nd ed., pp. 417-435). New York: Guilford Press.

Jahng, N., Krug, D., \& Zhang, Z. (2007). Student achievement in online distance education compared to face-to-face education. The European Journal of Open and Distance Learning, 2007-I. Retrieved September 21, 2011 from http://www.eurodl.org/materials/contrib/2007/Jahng_Krug_Zhang.pdf.

Jonassen, D. H., \& Grabowski, B. L. (1993). Handbook of individual difference, learning, and instruction. Hillsdale, NJ: Lawrence Erlbaum Associates.

Jung, C.G. ([1921] 1971). Psychological types, Collected Works, Volume 6, Princeton, N.J.: Princeton University Press.

Kim, B. S., \& Atkinson, D. R. (2002). Asian American client adherence to Asian cultural values. Journal of Counseling Psychology, 46, 3-14.

Means, B., Toyama, Y., Murphy, R., Bakia, M., \& Jones, K. (2010). Evaluation of evidence-based practices in online learning: A meta-analysis and review of online learning studies. U. S. Department of Education Office of Planning, Evaluation, and Policy Development Policy and Program Studies Service, 1-66.

Mischel, W. (1968). Personality and assessment. New York: Wiley.

Moberg, P. J. (2001). Linking the strategy to the five-factor model: Theoretical and empirical foundations. International Journal of Conflict Management, 12(1), 47-68.

Mount, M. F., \& Barrick, M. R. (1995). The big five personality dimensions: Implications for research and practice in human resource management. Research in Personnel and Human Resources Management, 13, 153-200. 
Ones, D. S., \& Viswesvaran, C. (1996). Bandwidth-fidelity in personality measurement for personnel selection. Journal of Organizational Behavior, 17, 609-626.

Pashler, H., McDaniel, M., Rohrer, D., \& Bjork, R. (2009). Learning styles, concepts and evidences. Psychological Science in the Public Interest, 9(3), 105-119.

Peterson, M. (2009). Learner interaction in synchronous CMC: A sociocultural perspective. Computer Assisted Language Learning, 22(4), 303-321.

Poropat, A. (2009). A meta-analysis of the five-factor model of personality and academic performance. Psychological Bulletin, 135(2), 322-338.

Ree, M. J., \& Earles, J. A. (1991). Predicting Training Success: Not Much More than g. Personnel Psychology, 44, 321-332.

Rowold, J. (2007). The impact of personality on training-related aspects of motivation: Test of a longitudinal model. Human Resource Development Quarterly, 18, 9-31.

Sapp, D. A., \& Simon, J. (2005). Comparing grades in online and face-to-face writing courses: Interpersonal accountability and institutional commitment. Computers and Composition, 22, 471-489.

Sitzmann, T., Brown, K. G., Casper, W. J., Ely, K., \& Zimmerman, R. D. (2008). A Review and MetaAnalysis of Trainee Reactions. Journal of Applied Psychology, 93, 280-295.

Sitzmann, T., Kraiger, K., Stewart, D., \& Wisher, R. (2006). The comparative effectiveness of web-based and classroom instruction: A meta-analysis. Personnel Psychology, 59, 623-664.

Smith, D. E., \& Mitry, D. J. (2004). Investigation of higher education: The real costs and quality of online programs. Journal of Education for Business, 83(1), 147-152.

Stone-Romero, E. F. (2011). Research strategies in industrial and organizational psychology. In S. Zedeck (Ed.), APA handbook of industrial and organizational psychology (Vol. 1, pp. 37-72). Washington, DC: American Psychological Association.

Thompson, E. R. (2008). Development and validation of an international English big-five mini-markers. Personality and Individual Differences, 45(6), 542-548.

Vamosi, A. R., Pierce, B. G., \& Slotkin, M. H. (2004). Distance learning in an accounting principles course - student satisfaction and perceptions of efficacy. Journal of Education for Business, 79(2), 360-366.

Varela, O. E., Cater, J. J., \& Michel, N. (2011). Similarity attraction in learning contexts: An empirical study. Human Resource Development Quarterly, 22(1), 49-68.

Vonderwell, S., \& Zachariah, S. (2005). Factors that influence participation in online learning. Journal of Research on Technology in Education, 38(2), 213-230.

Welsh, E. T., Wanberg, C. R., Brown, E. G., \& Simmering, M. J. (2003). E-learning: emerging uses, empirical results and future directions. International Journal of Training and Development, 7, $245-258$. 